\title{
Establishing and accessing referents in discourse
}

\author{
GREGORY L. MURPHY \\ Brown University, Providence, Rhode Island
}

\begin{abstract}
Four experiments explored the processes by which people understand references. Subjects read naturalistic stories one sentence at a time, and their reading-comprehension times were recorded. The first two experiments investigated differences between definite and indefinite reference. Their results suggest that establishing a new discourse referent (as indicated by an indefinite article or pronoun) produces longer comprehension times than referring to an already existing referent. The last two experiments investigated reference to one versus two discourse referents. They showed that accessing more referents led to longer reading times even when the referring sentences were identical. The results are explained in terms of a discourse model approach to comprehension. According to this view, readers construct a mental model of the discourse domain, and the ease of comprehension is related (in part) to the number of elements in the model that are accessed and the operations performed on them.
\end{abstract}

Reference is one of the primary functions of communication. From the prelinguistic pointing of young children to the use of elaborate descriptions in fluent adults, people find it necessary to pick out individual entities or groups of entities. It is no surprise, then, that linguists, philosophers, and psychologists have devoted much effort to devising an account of reference. This task is a difficult one because it requires (eventually) an explanation of how language corresponds to the world, and that correspondence is anything but straightforward. For psychologists, the problem of understanding reference raises issues of memory representations, linguistic processes, perception, and reasoning.

One recent approach to explaining reference has been the use of mental "discourse models." As a listener understands some discourse, he or she builds a mental world that represents the information in the discourse, and reference is made by picking out objects in this model of the world. A reference to something that is not in the model will not be understood, or else will require work on the part of the listener to alter the model. Johnson-Laird and Garnham (1980) demonstrated that this approach can account not only for "normal" reference, but also for reference to nonexistent objects or to objects that are misdescribed (cases that have posed serious problems for some past theories).

For example, someone might say at a crowded party,

(1) The man in the cheap suit is a gangster.

I would like to gratefully acknowledge the advice of Herbert Clark on these experiments and the helpful comments of Richard Gerrig, Raymond Gibbs, and Ed Wisniewski on an earlier draft of this paper. This research was supported by a BioMedical Research Grant from Brown University and by Grant MH-20021 to Herbert Clark. Requests for reprints may be addressed to Gregory L. Murphy, Hunter Laboratory of Psychology, Brown University, Providence, RI 02912. and successfully refer to the desired person, even when the man is not wearing a cheap suit (perhaps it just looks cheap, or perhaps it is not really a suit). Furthermore, the reference may be successful even if the speaker and the hearer both know that the description is false (Clark \& Marshall, 1981). These cases can be handled by the simple fact that people's discourse models can include objects and information that do not correspond to objects and facts of the real world. If the speaker and listener have similar models, then an incorrect description may still pick out one element sufficiently for comprehension (Clark \& Carlson, 1981; Clark \& Marshall, 1981; Johnson-Laird \& Garnham, 1980).

Another useful result of considering understanding to involve such discourse models is that this approach may help explain how people understand potentially ambiguous, vague, or difficult texts (see Collins, Brown, \& Larkin, 1980, and Johnson-Laird, 1981). Because the discourse model is a sort of mental world, people can use their real-world knowledge to organize and supplement it. The use of mental models in problem solving and reasoning was reviewed by Gentner and Stevens (1983).

Much of the support for this approach to language comprehension comes from studies of ambiguous or anomalous reference. The experiments described in this article focus on simpler cases of "normal" reference. In particular, this approach suggests that an important factor in understanding is whether the referent is already included in the discourse model. In most cases, a definite reference will in fact pick out something already in the model-that is, something that has been mentioned in the discourse or that is present in the context (Clark \& Marshall, 1981). Usually, indefinite references introduce a new entity into the conversation. When the listener hears an indefinite article (or no article for plural nouns), he or she can guess that a new entity is being mentioned and that a new element in the discourse model must 
be created. All other things being equal, it should therefore take longer for listeners to understand indefinite references than to understand definite references. Experiments 1 and 2 investigated this claim.

Another implication of this approach is that reference to more than one object in the discourse model should take longer than reference to a single object. Since the entities in the discourse model are in fact separate "objects," picking out two or more of them should be more time consuming than picking out one, even when the multiple objects are described by a single noun. This hypothesis was elaborated and investigated in Experiments 3 and 4.

Although the experiments described here were inspired by the discourse-model approach to comprehension, their primary goal was not to evaluate that approach as a whole, but to investigate specific hypotheses about reference. There is no single theory of the use of discourse models in understanding (which is why I have been calling it an "approach," rather than a "theory"), and different instantiations of the approach could be devised to make different predictions than those I give. These experiments can be thought of as providing data on which more detailed accounts of understanding can be based in any theoretical framework, although they are particularly relevant to the discourse-model approach.

There are a number of alternative theories of reference that may suggest other psychological explanations of how reference is understood. However, like the discoursemodel approach, these theories usually do not provide the necessary detail to make clear predictions for on-line measures of comprehension. Rather than describing alternative approaches here, I consider more specific alternatives for the individual reference processes of the separate experiments.

\section{EXPERIMENT 1}

As Clark and Marshall (1981) showed in detail, understanding definite reference can often involve complex reasoning about possible referents based on the hearer's knowledge of the domain of discourse and of the speaker (see also Clark \& Murphy, 1982). Definite reference cannot be interpreted through syntactic rules, although there are some syntactic constraints on reference (see, e.g., Lasnik, 1976). Furthermore, it cannot be interpreted solely through semantic analysis of the referring expression. As mentioned above, the noun phrases used to refer are often vague, ambiguous, or even incorrect from an "objective" viewpoint [as in (1)]. It is only by virtue of similar discourse models (and similar processes to act on them) that speaker and hearer can communicate.

If the discourse model is a mental representation containing various elements with associated schemata, then introducing a new element will require the model to be updated. Simply referring to an already established element will not require such a change, and thus should be easier and faster to do. In order to test this prediction, it is necessary to construct passages that either invoke a new element or refer to an old element, with the referring expressions carrying the same amount of information. That is, it is important not to confound the complexity of the expression or its meaning with the factor of interest. Experiment 1 therefore compared noun phrases in identical contexts that differed only in the use of the definite or indefinite article.

Experiment 1 used the reading-time paradigm, in which subjects read stories, a sentence at a time, and pressed a button as they understood each sentence. One story contained the following sequence in which the article was varied for different subjects:

(2) Though driving 55, Steve was passed by a truck. Later, George was passed by a/the truck too.

Notice that the same actions and properties are predicated in both versions. Furthermore, both versions repeat the noun in the second sentence (i.e., although the indefinite version introduces a new object, it does not introduce a totally new concept). The only difference between the two is whether the actions and properties are predicated of a new object or of one already mentioned, as signaled by the article.

An alternative hypothesis is that the definite article prompts the reader to search memory for the object being referred to, whereas the indefinite article indicates that a new object is being mentioned and thus no such search is necessary (Irwin, Bock, \& Stanovich, 1982). Therefore, indefinite reference should be easier to comprehend. This hypothesis has some plausibility, and it may be true when the definite reference is only obscurely related to its referent. However, the main hypothesis assumes that finding the antecedent of a simple definite reference should be easier than establishing a whole new referent in the discourse model.

Other investigators have looked at various effects of definite and indefinite articles, but apparently never in order to investigate instantiation of referents. A number of experiments have suggested that memory for text is organized around discourse referents, rather than individual sentence meanings (Bransford, Barclay, \& Franks, 1972; de Villiers, 1974; Ehrlich \& JohnsonLaird, 1982; Garnham, 1981), but they do not address the questions of understanding processes raised here.

More recently, Irwin et al. (1982) showed that the article preceding a noun influenced the time it took to perform a lexical decision on the noun, in particular, that the lexical decision was facilitated by a preceding definite article. Although these results are consistent with the predictions made here, their experiment did not actually measure sentence comprehension, but, rather, identification of a single test word. It is conceivable that their results derived from strategies operating in the lexical decision task that would not be as important in a more naturalistic reading situation. Experiment 1 reproduced the normal 
reading situation more closely, in an attempt to replicate their results.

Finally, an experiment by Haviland and Clark (1974) may be the closest conceptually to Experiment 1. In their Experiment 2, they compared (3) and (4).

(3) Ed was given an alligator for his birthday The alligator was his favorite present.

(4) Ed wanted an alligator for his birthday The alligator was his favorite present.

They found that the second sentence of (4) took longer to understand than that of (3), presumably because an actual alligator had already been established in (3). However, the definite noun phrase is somewhat anomalous in (4), since it is being used to introduce an element rather than to refer to an old one. So, this difference in comprehension times may reflect either the time to establish a new discourse referent or the time to override the anomaly (or both). Experiment 1 eliminated this potential problem.

\section{Method}

Subjects. The subjects were 18 Brown University undergraduates who were paid for their participation.

Materials. Eighteen stories were used, each 11 lines long, with a truefalse question at the end. Each story contained two test sentences, which were always the 5th and 10th lines. Two versions of each story were created; they differed in whether an indefinite or definite article was used in the test sentences (and also in the following sentence of the story, to be consistent with this difference). See Appendix A for an example. Because definite and indefinite reference are ubiquitous in all texts, the presence of test sentences was opaque to the subjects, who never reported guessing the purpose of the experiment in the debriefing session. (In fact, this is true of all of the experiments.) Each line of the story contained a complete sentence or clause.

The true-false question following each story was written to ensure that the reader had paid close attention to the story. The questions did not, however, always focus on the test sentences, since that might have given away the focus of the study. For this reason, these questions could not be used to monitor the readers' interpretations of the referring expression. (Since there were two test sentences per story, this would also have required more than one question for each story.)

Procedure. The subjects read the instructions at the beginning of the experiment. The instructions explained the task and emphasized that the subjects should fully understand each sentence before pressing the button to begin the next presentation. The subjects then repeated the instructions to the experimenter, who corrected any misconceptions and added any missing information. The subjects then read four practice stories, after which the instructions were reemphasized. These instructions were designed to encourage the subjects to complete any processes of assigning referents so that they would be included in the comprehension times.

The stories were presented on a standard video monitor controlled by an Apple II + microcomputer, in upper- and lowercase print. Each story presentation began with the message "PUSH BUTTON FOR NEXT STORY." After the subjects depressed the response key, there was a 2 -sec delay, followed by a plus sign as a fixation point. For each line of the story, the fixation point appeared for $750 \mathrm{msec}$, followed by a 250 -msec blank screen and then the sentence. The sentence disappeared after the subjects' responses, and, $500 \mathrm{msec}$ later, the fixation plus reappeared. The computer recorded the reading time of each sentence. At the end of the story, the true-false question appeared, and the subjects responded by pressing a "true" or a "false" button on the response panel. The time of this response was not recorded. The order of the stories was determined randomly for each subject, and half of the subjects were assigned at random to each story version.

\section{Results and Discussion}

The reading times did show an effect of the definite and indefinite article: Sentences with the definite article took $1,556 \mathrm{msec}$ to understand, and those with the indefinite article took $1,764 \mathrm{msec}$. This 208 -msec difference was reliable in the subject analysis $[\mathrm{F}(1,17)=7.01, \mathrm{p}<.02$, $\mathrm{MSe}=6,159]$ and in the item analysis $[\mathrm{F}(1,35)=5.62$, $\mathrm{p}<.025, \mathrm{MSe}=6,726$ ].

Thus, as Haviland and Clark (1974) found, people took longer to read and comprehend sentences that mentioned a new object than sentences that referred to an old one. This experiment rules out the problem of misuse of the definite article that may have been present in Haviland and Clark's experiment. Moreover, it found an effect of article definiteness similar to that of Irwin et al. (1982), who used a lexical decision task. The effect here (208 msec) was much larger than any found in their experiments (their largest analogous effect was $46.5 \mathrm{msec}$, in Experiment 4). Possible reasons for this difference are discussed after Experiment 2.

The results also argue against the alternative hypothesis that definite reference should be more difficult than indefinite reference, since it requires the reader to find an antecedent. Apparently, the time needed to establish a new element overrides any such effect. It should be noted, however, that the references here were all straightforward ones requiring no difficult inferences. Direct references involving extensive or tenuous inferencing may well take longer than indirect references, which usually do not require such computations.

The results of Experiment 1 do not definitely establish the discourse-model explanation of how the article affected the understanding process. Another possibility is that the definite article facilitates the perception and interpretation of the following noun: When readers encounter the, they may activate memory representations of words or concepts that have already been mentioned and that match the repeated noun. Since the indefinite article usually indicates the introduction of a new referent, it would not engender this activation. Experiment 2 attempted to tease apart these two possibilities, eliminating the articles but retaining the contrast between definite and indefinite reference, by using pronouns.

\section{EXPERIMENT 2}

The understanding of pronouns must be similar in many ways to the interpretation of full noun phrases. For both, the listener must try to pick out a referent based on the context and the information in the referring expression. For pronouns, that information is restricted primarily to number, gender, and animacy; noun phrases can contain as little information as a pronoun, or considerably more. Like noun phrases, pronouns differ in their definiteness: Personal pronouns are all definite; indefinite pronouns include one(s) and some. Compare: 
(5) a. Sandy rode a bicycle and I rode it too.

b. Sandy rode a bicycle and I rode one too.

The definite pronoun it refers to the previously mentioned bicycle; the indefinite pronoun one refers to a new bicycle.

Experiment 2 used definite and indefinite pronouns to extend the results of Experiment 1. For example, Experiment 2 compared the two versions of (6) embedded in a story,

(6) Karen gave money to an old woman.

Dan gave her/one some money too.

In general, the indefinite pronoun one was contrasted with the grammatically appropriate definite pronoun, she, him, $i t$, etc. Because definite and indefinite articles were not varied here, and because there was no repeated noun phrase, any perceptual facilitation or guessing strategy that may have occurred in Experiment 1 could not operate in Experiment 2.

A second factor in Experiment 2 was the length of the antecedent. Because the pronoun may in some way "reinstate" its antecedent (Frederiksen, 1981), the length of the antecedent might be expected to influence its comprehension. Furthermore, this effect might be particularly pronounced for indefinite pronouns, since they require the instantiation of a new element that corresponds in some way to the antecedent. The full reasoning behind this prediction is described in Murphy (1982, in press); because of the equivocal results, it will not be fully discussed here.

\section{Method}

Subjects. Twenty Stanford University undergraduates performed the experiment to fulfill a course requirement.

Materials and Procedure. Twenty stories similar to those used in Experiment 1 were constructed. Each story contained two test sentences, one containing a definite and the other containing an indefinite pronoun (varied between subjects). The indefinite pronoun was always one; the definite pronoun was the grammatically appropriate counterpart. These sentences were preceded by a sentence containing an antecedent that was either long or short. The two versions of the antecedent noun phrase had the same head nouns, but the long version contained additional adjectives and adjective phrases or a relative clause modifying the noun. Appendix B contains an example. Four different lists of the stories were created so that each test sentence appeared in all conditions. Equal numbers of subjects received each version.

The procedure was identical to that of the first experiment.

\section{Results and Discussion}

The mean reading times are presented in Table 1. The main result is that the effect of definiteness found in Ex-

Table 1

Mean Reaction Times (in Seconds) for Experiment 2 as a Function of Pronoun Type and Length of Antecedent

\begin{tabular}{lcr} 
& \multicolumn{2}{c}{ Antecedent } \\
\cline { 2 - 3 } Pronoun & Long & Short \\
\hline Definite & 1.594 & 1.509 \\
Indefinite & 1.856 & 1.820 \\
\hline
\end{tabular}

periment 1 was replicated: Sentences with indefinite pronouns took $287 \mathrm{msec}$ longer to read than those with definite pronouns $[\mathrm{F}(1,19)=17.79, \mathrm{p}<.001, \mathrm{MSe}=$ .0926 , in the subject analysis; $F(1,39)=13.58, p<.001$, MSe $=.2454$, in the item analysis]. This result suggests that the effect of definiteness cannot be completely caused by the presence of the definite article, since in Experiment 2 definiteness was varied by the pronoun rather than by an article. (Of course, this does not mean that the definite article does not have a facilitative effect, but it argues that the addition of a discourse element influences understanding beyond that.)

This effect also rules out another alternative explanation for Experiment 1's results (and those of Irwin et al., 1982). Perhaps subjects were disturbed by the repetition of a noun that was not coreferential with its first occurrence. That is, if people read the word bicycle twice, they may expect both occurrences to refer to the same object. In the indefinite condition, however, the words refer to different objects, and it might have been this violated expectation that slowed reading, rather than the instantiation of a new discourse element. Contrary to this hypothesis, Experiment 2 found a similar effect, with no lexical repetition.

There was only a small and nonsignificant effect of antecedent length $[\mathrm{F}(1,19)=2.02, \mathrm{p}>.10, \mathrm{MSe}=.0358$, over subjects; $\mathrm{F}(1,39)=.28, \mathrm{p}>.50, \mathrm{MSe}=.2652$, over items]. Because the $60-\mathrm{msec}$ effect was in the expected direction, it may be premature to affirm the null hypothesis here. More convincing was the finding of no interaction of definiteness and antecedent length (both Fs $<1.0 ;$ MSe $=.0443$ and .0723 for subject and item analyses, respectively). One possible result discussed above was that antecedent length would affect any new discourse elements being instantiated and thus would have a greater effect for indefinite than for the definite pronouns. However, the interaction was nonsignificant, and the means actually go in the opposite direction (see Table 1).

The advantage of definite reference in Experiments 1 and 2 was an order of magnitude larger than that found by Irwin et al. (1982). This may not be surprising, given that Irwin et al. used a task quite different from the reading-time procedure used here. Their lexical decision task was probably sensitive to perceptual and semantic facilitation caused by the definite article, among other factors. However, because subjects were instructed to judge as quickly as possible whether or not the test string was a word, the lexical decision times may not have reflected all the discourse processes that were operating. Even so, the finding of an advantage of definite reference in both paradigms is good converging evidence. The result from Experiment 2, that this advantage does not depend on the presence of articles, adds further evidence that instantiating new discourse elements has a measurable effect.

As a whole, the results give more evidence for the importance of instantiating new discourse elements, but lit- 
tle evidence for any reinstatement of the linguistic antecedent in understanding pronouns, due to the null effect of antecedent length. (However, the latter finding is ambiguous enough to require confirmation in future research.) Assuming that the null effect of antecedent length is "real," it may pose a problem: If indefinite reference involves creating new objects in the model, one might expect the antecedent to influence how much new information needs to be added. The complete absence of an effect of length on indefinite pronouns is a little mystifying. One possible answer is to make a distinction between descriptions and objects in the mental model similar to the type-token distinction. (Garrod \& Sanford, 1977, p. 88, also made this distinction.) Indefinite anaphoric reference introduces a new object but uses the same description as some other object (see Webber, 1979). Thus, in Dan gave one some money too, one refers to a new object, but the object is identified by a description (old woman, or whatever) already mentioned. To interpret one, the subject may have discovered the antecedent and added a new element with a pointer to the description already present, which would produce no effect of antecedent length, but which would find an influence of definiteness. This process would be more efficient than reinstating all the information associated with the antecedent, since it would not require the reader to represent information redundantly. Experiments 3 and 4 further investigated the question of economy in discourse representation.

\section{EXPERIMENT 3}

Experiments 1 and 2 found differences between reference to an element and instantiation of a new element in the discourse model. But even within the realm of reference to an already established element, there may be differences in what references are easy to understand. Other research has found effects of referential continuity (Ehrlich \& Johnson-Laird, 1982), the typicality of the concept being referred to (Garrod \& Sanford, 1977), the plausibility of the reference (Marslen-Wilson \& Tyler, 1980), the focus of antecedents (Shwartz, 1981; Yekovich, Walker, \& Blackman, 1979), the distance of antecedents (Clark $\&$ Sengul, 1979), and so on. Experiments 3 and 4 further explored the notion of objects in a discourse model by comparing reference to one versus two discourse elements. The discourse-model approach suggests that referring to one element will require less processing than referring to two or more: If discourse understanding is centered around referents, then the more referents a sentence includes, the more processing it should require to be understood. An important consideration here is to control for the total amount of information presented-that is, not to present twice as many propositions when two elements are referred to.

Experiment 3 attempted to investigate this hypothesis by comparing sentences with plural and singular noun phrases that evoked either one or two discourse entities, respectively. Notice, however, that not all plural nouns refer to two (or more) elements in the discourse model even if they refer to many objects in the world. For example, consider the delegates in the following.

(7) Each of the 50 states elected a delegate to the convention. Unanimously, the delegates voted against the exclusion rule.

It seems unlikely that readers establish a separate entity for each delegate referred to-not only would this exceed memory capacity, but it is also unnecessary, since the delegates are not differentiated in any way. Rather than 50 elements, the reader probably establishes one element for the whole set of delegates (Johnson-Laird, 1983, p. 443 , discusses a number of such possibilities).

The stories used here were designed to avoid the "set" interpretation of plurals as much as possible. First, the plurals referred to only two entities, rather than to a large number. It should be relatively easy to establish two discourse entities, whereas it may be impossible to differentiate larger numbers of similar objects or people in a story. Second, the two objects were given differentiating descriptions. In a story describing two children, one was described as Japanese and pretty, the other as noisy; for two paintings, one was a landscape and one was brightly colored. Providing different information about each element should cause subjects to represent them separately to avoid confusing them.

In the singular condition, the information predicated of the two objects was simply predicated of one object. Thus, the differentiating propositions were different, but not contradictory. In this way, the total amount of information presented was roughly equal in the two versions. Following is one of the stories in both of its versions.

(8) Linda was looking for a new house.

There were a lot of houses for sale in her town.

She visited a house with a fireplace in every room.

It was only a block away from the train station.

The house was far too expensive, however.

She decided to stay in her old place after all.

(9) Linda was looking for a new house.

There were a lot of houses for sale in her town.

She visited a house with a fireplace in every room.

Another was only a block away from the train station.

The houses were far too expensive, however.

She decided to stay in her old place after all.

The test sentence (the fifth) varied only in the plurality of the noun and in verb agreement (when the noun was the subject of the sentence). The two versions of this sentence seem to contain the same number of propositions (as measured, e.g., by methods used by Kintsch \& van Dijk, 1978).

One might argue that syntactic or morphological differences between plurals and singulars could lead to slower comprehension of the plurals. It seems unlikely that such 
factors would have effects of much magnitude, but Experiment 4 provided more substantial evidence for this assumption.

\section{Method \\ Subjects. Sixteen Stanford undergraduates fulfilled a course require- ment by participating in the experiment. \\ Materials and Procedure. Two versions of 20 new stories were con- structed. One version mentioned a single object and predicated (at least) two propositions about that object, and the other mentioned two objects and predicated (at least) one of those propositions about each one. The stories were six lines long, with the test sentence always on the fifth line. The test sentences were identical in the two versions except for the plurality changes. Each subject read only one version of each story, and half of his or her stories were singular, half plural. \\ The procedure was the same as in the previous experiments.}

\section{Results and Discussion}

The plurality change did affect the reading times of the target sentences. For singular sentences, the mean reading time was $1,728 \mathrm{msec}$; for the plural sentences, it was $1,919 \mathrm{msec}$. This difference was highly significant over subjects $[\mathrm{F}(1,15)=14.82, \mathrm{p}<.003, \mathrm{MSe}=.0197]$ and just at the significance level over items $[\mathrm{F}(1,19)=3.97$, $\mathrm{p}=.058, \mathrm{MSe}=.0918]$. The lack of full significance probably reflects the smaller number of items used here than in Experiments 1-2, which had two test sentences in each story. The results suggest that accessing two referents in interpreting a noun phrase does take more time than accessing one. Experiment 4 ruled out some alternative explanations for this effect.

\section{EXPERIMENT 4}

As discussed earlier, not all plurals refer to more than one element of a discourse model. Some of them appear to engender a "set" interpretation, in which a single element refers to a set of individuals that share a single description. This representation seems necessary to avoid memory overload; if the objects can all be described by the same propositions, there is little need to represent each separately.

The explanation I suggested for Experiment 3 was that referring to more than one discourse element would take longer than referring to one. However, alternative accounts focus on other differences between plurals and singulars. Experiment 4 avoided those possible confounds by using only plural noun phrases, varying the context so that they sometimes referred to a set of identical objects and sometimes to two differentiated objects. I call these conditions the set and individuals interpretations of the plural, respectively. The individuals condition was based on the plural versions of the stories used in Experiment 3 . The set versions were constructed so that the same propositions were expressed about a group of objects. Compare (10) below with the individuals version in (9).

(10) Linda was looking for a new house.

There were a lot of houses for sale in her town.

She visited several houses with fireplaces in every room.
They were just several blocks away from the train station.

The houses were far too expensive, however.

She decided to stay in her old place after all.

Notice that the crucial (fifth) sentence is identical in the two versions, but that they differ in their interpretation of the houses. In (9), the individuals condition, it refers to the two houses just mentioned; in (10), the set condition, it refers to a group of similar houses, their exact number unspecified. Note also that the sentences preceding the crucial one in the two versions are as identical as possible.

If the results of Experiment 3 were due to the length, morphological characteristics, etc., of the plural, then Experiment 4 would have been expected to find no differences between the two versions. If readers are sensitive to the number of discourse elements being referred to, then the individuals condition should produce longer reading times than the set condition, even though the test sentences are identical.

\section{Method}

Subjects. Eighteen Brown University undergraduate and graduate students performed the task for pay.

Materials. The 19 stories were modified from those used in Experiment 3 to generate a set and individuals plural version of each, as described above. Because of the preponderance of plurals in these stories, 15 filler stories involving a single person or object were added to prevent subjects from noticing this fact.

Procedure. The procedure and apparatus were identical to those of Experiment 1. For each story, half of the subjects received the set version, and half the individuals version.

\section{Results and Discussion}

The plural sentences with a set interpretation took $1,812 \mathrm{msec}$ to read, whereas those with an individuals interpretation took $1,953 \mathrm{msec}$. This 141 -msec difference was reliable $[\mathrm{F}(1,17)=4.58, \mathrm{p}<.05, \mathrm{MSe}=4,362$, over subjects; $\mathrm{F}(1,18)=5.23, \mathrm{p}<.05, \mathrm{MSe}=3,858$, over items].

Apparently, the plurals referring to differentiated individuals did generate multiple discourse elements, which took longer to access in understanding. Since the test sentences were identical in the two conditions, these results cannot be attributed to linguistic or perceptual differences, but must be due to what the sentences refer to.

These results seemingly conflict with the claims of Johnson-Laird (1981, 1983), who argued that statements like "All the beekeepers are gardeners" are represented by a number of separate elements representing beekeepers and gardeners. Johnson-Laird used this assumption to explain subjects' performance in evaluating syllogisms with quantifiers. But since the beekeepers are presented as an undifferentiated set, the results of Experiment 3 suggest that they should be represented as a single discourse element. However, there need not be a conflict here: In Johnson-Laird's task, subjects realized that they were being given a reasoning test. His results may be true for tasks set up as syllogistic reasoning tests, and the results 
presented here may hold for more neutral reading situations. (Also, the need to establish many discourse elements to explain reasoning is crucial only when quantifiers like some are used to distinguish members of a class. In this case, the two theories agree that separate elements must be created.) Similarly, the elaborate mental models used in solving physics problems (e.g., Gentner \& Gentner, 1983; Larkin, 1983) may not be employed in understanding nontechnical discourse involving those concepts. These possible differences between casual discourse and structured reasoning situations deserve more empirical research.

The stories in Experiments 3 and 4 were carefully controlled so that equivalent information was presented in each condition before the test sentence. This was done so that the differences between the versions could not be explained as the difficulty in accessing the propositions of previous sentences or the like. However, there is a possible discourse-level explanation different from the one suggested earlier, based on a "distance effect." In the plural stories referring to two objects [e.g., (10)], the third sentence introduces one referent, the fourth sentence introduces another, and the fifth sentence refers to both of them. In the singular and set versions, however, only one referent is introduced and discussed in the third and fourth sentences. Thus, the difference between these conditions could have either of two causes: It could take longer to access two discourse elements than one (as I have argued), or it could take longer to access a referent that has not been mentioned for a sentence (the first referent in the individuals condition) (see Clark \& Sengul, 1979). Note that the two explanations have similar assumptions about discourse referents-they differ primarily in the mechanisms that access referents.

These two explanations make nearly identical predictions for normal stories, because any text that introduces two separate referents is likely to have one mentioned later than another, whereas a similar text about one referent will not have this problem. In spite of this similarity, Experiments 3 and 4 gave some evidence that favors the number-of-elements explanation. In the plural version of (9), the following two sentences preceded the test sentence: She visited a house with a fireplace in every room. Another was only a block away from the train station. Although the two sentences focus on two different houses, notice that the second one actually refers to both of them. That is, the elliptical Another means another house. In order to understand this sentence, the reader had to access a representation of the first house. Therefore, even though this sentence is not about both houses, readers probably had access to both discourse elements when processing it. Other stories were very similar in this regard: The second sentence used pronouns or elliptical NPs that referred to the first element while establishing a new one.

The point of this discussion is to show that the first referent was probably not as "distant" as might seem at first glance, since readers probably evoked it to understand the sentence with the second referent. In fact, in order to get a clear distance effect, Clark and Sengul (1979) were careful to eliminate such implicit references in their experiments on the distance of antecedents. The stories in the current experiments did make such implicit references, and therefore probably eliminated the distance effect. This reasoning suggests that the number-ofreferents explanation is more likely here. However, in natural texts, both factors probably affect understanding.

\section{GENERAL DISCUSSION}

All four experiments demonstrated the importance of reference in comprehension. Readers attend to separate referents and establish new referents when they are introduced, and these processes take measurable amounts of time. Referential processes cannot be cued by syntactic features of the sentence: Whether an expression establishes a new referent or refers to one, two, or more discourse elements can be computed only by relating it to the previous discourse and the context. Even the linguistic markers of referential status are not perfect indicators - plurals can sometimes refer to one discourse element, and the definite article may sometimes be used to introduce a new element (Haviland \& Clark, 1974). These considerations suggest that people must use something like a discourse model to keep track of the referents when interpreting discourse.

Experiments 1 and 2 showed that understanding indefinite noun phrases and pronouns took longer than understanding definite references. This finding suggests that when a new referent is mentioned, the reader must establish a new element for it and connect it with the other elements in the model. Furthermore, Experiment 2 found that establishing an elaborated new element took no more time than establishing a simple one (varied through pronoun antecedents). This can be explained by the efficient use of descriptions already in memory-apparently, people can establish a new referent without having to rewrite all of the information associated with it, if that information is already in memory.

Experiment 4 confirmed the use of such an efficient representation for sets of objects. When two objects with different descriptions were evoked in the text, two separate elements were created. When a group of objects having identical descriptions were evoked, they were represented by one element.

Experiments 3 and 4 also provided insight into processes of understanding definite reference. Their results showed that sentences that referred to two discourse elements took longer to understand than those that referred to one element. This occurred when the same number of propositions was expressed in each sentence and even when the sentences were identical. This result gives more evidence that people structure their memory for discourse around referents, and that they access the referents in understanding the sentence.

Considered together, the experiments suggest the following account of reference by plural noun phrases. When a noun phrase refers to a homogeneous set of objects, 
reference is similar to that of a singular noun phrase. That is, the single discourse element that represents the objects is picked out. When a noun phrase picks out differentiated entities, the reader accesses each of them and connects them to the new predicate expressed in the sentence. It seems most likely that this predicate is represented only once in memory but is linked to all referents.

Natural texts include more complex discourse elements, such as plurals that refer to multiple sets. For example, a text might discuss 50 senators, distinguishing in some detail many groups of senators (e.g., Southern Democrats, right-wing Republicans, industrial-state senators, etc.). It might be impossible to keep each group separate in a discourse model. Perhaps, in such cases, readers construct a complex memory network of which only part is in active memory at any time. In this example, there might be a single element for all the senators, which is connected to elements representing the various subgroups (which themselves may be connected by various relations). When the reader encounters a sentence about the senators as a whole, the single element for all the senators may be accessed, rather than the element for every subgroup. This account seems compatible with many theories of knowledge representation (e.g., Anderson, 1976; Norman \& Rumelhart, 1975; Schank, 1982), but those theories have not addressed the implications of such representations for reference in discourse. Clearly, more experimentation is required to find evidence for this account and to flesh out the details of how reference is made to complexly related sets of objects.

\section{REFERENCES}

ANDERSON, J. R. (1976). Language, memory and thought. Hillsdale, NJ: Erlbaum.

Bransford, J. D., Barclay, J. R., \& Franks, J. J. (1972). Sentence memory: A constructive versus interpretive approach. Cognitive Psychology, 3, 193-209.

ClaRK, H. H., \& CARLSON, T. B. (1981). Context for comprehension. In J. Long \& A. Baddeley (Eds.), Attention and performance $I X$ (pp. 313-330). Hillsdale, NJ: Erlbaum

Clark, H. H., \& Marshall, C. R. (1981). Definite reference and mutual knowledge. In A. K. Joshi, B. L. Webber, \& I. A. Sag (Eds.), Ele ments of discourse understanding. Cambridge: Cambridge University Press.

Clark, H. H., \& MURPHY, G. L. (1982), Audience design in meaning and reference. In J. F. LeNy \& W. Kintsch (Eds.), Language and comprehension (pp. 287-299). Amsterdam: North-Holland

ClaRK, H. H., \& SENGUl, C. J. (1979). In search of referents for nouns and pronouns. Memory \& Cognition, 7, 35-41.

Collins, A., BROWN, J. S., \& LARKIN, K. M. (1980). Inference in text understanding. In R. J. Spiro, B. C. Bruce, \& W. F. Brewer (Eds.)
Theoretical issues in reading comprehension (pp. 385-407). Hillsdale, NJ: Erlbaum.

DE VilLiERS, P. A. (1974). Imagery and theme in recall of connected discourse. Journal of Experimental Psychology, 103, 263-268.

EHrLich, K., Johnson-Laird, P. N. (1982). Spatial descriptions and referential continuity. Journal of Verbal Leaming and Verbal Behavior, 21, 296-306.

FREDERIKSEN, J. R. (1981). Understanding anaphora: Rules used by readers in assigning pronominal referents. Discourse Processes, 4, 323-347.

Garnham, A. (1981). Mental models as representations of text. Memory \& Cognition, 9, 560-565

GARROD, S., \& SANFORD, A. (1977), Interpreting anaphoric relations: The integration of semantic information while reading. Journal of Verbal Learning and Verbal Behavior, 16, 77-90.

GentNer, D., \& GentNer, D. R. (1983). Flowing waters or teeming crowds: Mental models of electricity. In D. Gentner \& A. L. Stevens (Eds.), Mental models (pp. 99-120). Hillsdale, NJ: Erlbaum.

GentNER, D., \& STEvens, A. L. (Eds.) (1983). Mental models. Hillsdale, NJ: Erlbaum.

Haviland, S. E., \& ClaRK, H. H. (1974). What's new? Acquiring new information as a process in comprehension. Journal of Verbal Learning and Verbal Behavior, 13, 512-521.

Irwin, D. E., Bock, J. K., \& Stanovich, K. E. (1982). Effects of information structure cues on visual word processing. Journal of Verbal Learning and Verbal Behavior, 21, 307-325.

Johnson-LalRD, P. N. (1981). Mental models of meaning. In A. K. Joshi, B. L. Webber, \& I. A. Sag (Eds.), Elements of discourse understanding (pp. 106-126). Cambridge: Cambridge University Press.

Johnson-Laird, P. N. (1983). Mental models. Cambridge, MA: Harvard University Press.

Johnson-LaIRD, P. N., \& Garnham, A. (1980). Descriptions and discourse models. Linguistics and Philosophy, 3, 371-393.

KINTSCH, W., \& VAN DuK, T. A. (1978). Toward a model of text comprehension and production. Psychological Review, 85, 363-394.

LARKIN, J. H. (1983). The role of problem representation in physics. In D. Gentner \& A. L. Stevens (Eds.), Mental models (pp. 75-98). Hillsdale, NJ: Erlbaum.

LASNIK, H. (1976). Remarks on coreference. Linguistic Analysis, 2, 1-22.

MARSLEN-Wilson, W., \& TYLER, L. K. (1980). Towards a psychological basis for a theory of anaphora. In J. Kreiman \& A. E. Ojeda (Eds.), Papers from the parasession on pronouns and anaphora. Chicago: Chicago Linguistic Society.

MURPHY, G. L. (1982). Understanding anaphora. Unpublished doctoral dissertation, Stanford University, Stanford, CA.

MURPhy, G. L. (in press). Processes of anaphoric understanding. Journal of Verbal Learning and Verbal Behavior.

Norman, D. A., \& RUMElhaRT, D. E. (1975). Explorations in cognition. San Francisco: Freeman.

Schank, R. C. (1982). Dynamic memory: A theory of reminding and learning in computers and people. Cambridge: Cambridge University Press.

SHWARTZ, S. P. (1981). In search of pronominal reference (Yale Cognitive Science Tech. Rep. 10). New Haven, CT: Yale University.

WEBBER, B. L. (1979). A formal approach to discourse anaphora. New York: Garland Press.

Yekovich, F. R., Walker, C. H., \& Blackman, H. S. (1979). The role of presupposed and focal information in integrating sentences. Journal of Verbal Learning and Verbal Behavior, 18, 535-548.

\section{Appendix A}

\section{Two Versions of a Story From Experiment 1}

Barry was in training for the US Olympic bicycle racing team.

He spent all his free time riding up and down nearby hills, and all his money on bicycles and bike equipment, as repairs were common.

Once his bicycle broke down.

Fortunately, he had a bicycle ready in time for the race.

He was glad to have brought an extra racing bike along. 
Many races were unpleasant because of poor conditions.

Often the weather was bad and the course lousy.

He once rode a rainy race.

He won the race in spite of the difficulty,

partly because there were accidents caused by the traffic.

Barry was in training for the US Olympic bicycle racing team.

He spent all his free time riding up and down nearby hills,

and all his money on bicycles and bike equipment, as repairs were common.

Once his bicycle broke down.

Fortunately, he had the bicycle ready in time for the race.

He was glad to have brought spare parts for his racing bike.

Many races were unpleasant because of poor conditions.

Often the weather was bad and the course lousy.

He once rode a rainy race.

He won a race in spite of the difficulty, partly because there were accidents caused by the traffic.

Note-The crucial lines are the 5th and 10th lines, although other lines differ slightly in the two versions to ensure consistency.

\section{Appendix B \\ Two Versions From Experiment 2}

Brian and Gordon were housesitting for a professor of theirs.

They had to stay for a week, but, after a day, they were bored.

They began to rollerskate through the halls before going outside.

Gordon slipped and hit a rare, wide, stained-glass window.

Brian slipped and hit one too.

The one Gordon hit broke, and he spent all afternoon trying to fix it.

They were still bored, so that night they raided the liquor cabinet.

They sat around the living room, drinking, smoking and watching t.v.

Brian's cigarette set a couch on fire.

Soon, Gordon's cigarette set it on fire as well.

Fortunately, Brian was sober enough to put out the fire.

Brian and Gordon were housesitting for a professor of theirs.

They had to stay for a week, but, after a day, they were bored.

They began to rollerskate through the halls before going outside.

Gordon slipped and hit a window.

Brian slipped and hit it too.

It broke when Gordon hit it, and he spent all afternoon trying to fix it.

They were still bored, so that night they raided the liquor cabinet.

They sat around the living room, drinking, smoking and watching t.v.

Brian's cigarette set a plush, modernistic couch from Denmark on fire.

Soon, Gordon's cigarette set one on fire as well.

They put Brian's fire out before long, but the other couch was ruined.

Note-The second version is the reverse of the first, in that the long antecedent is changed to a short one, and one is changed to it and vice versa. However, there are four such versions in the whole design, to fill out the combinations of factors. The crucial lines are again the 5th and 10th ones.

(Manuscript received February 2, 1984;

revision accepted for publication May 20, 1984.) 